\title{
Translation of Films under Newmark's Translation Theory
}

\author{
Wei Liu \\ School of Foreign Languages, Jilin Agricultural University, ChangChun 130118, China \\ 29897259@qq.com
}

Keywords: Translation of Films, Semantic Translation, Communicative Translation

\begin{abstract}
Recently, more and more attention has been paid to the translation of films. But because of its own characteristics, there is a dispute about what theories or strategies should be applied to the translation of films. This paper analyzed the characteristics of films, and discussed the translation under Newmark's translation theory.
\end{abstract}

\section{Introduction}

With the globalization, a large number of foreign films enter the Chinese market, and Chinese films also have access to going abroad. Due to the differences between languages and cultures, there must be some barriers to hinder audiences from understanding overseas films, which would have a negative impact on the pleasure of film appreciation. Therefore, the translation of films has drawn increasing academic attention.

\section{Characteristics of Film Languages}

Films belong to the category of literary works, but they are special literary works, which have their own characteristics. In terms of the characteristics of the film, as early as 1998, Professor Zhang Chunbai put them into the characteristics of the language of instant and mass (Zhang Chunbai, 1998: 50). Qian Shaochang in his article “Translation of Filmograpgy ---the Increasing Important Part in the Field of Translation” put five major characteristics of film language: listening, comprehensiveness, instant, popularity and no notes (Qian Shaochang, 2000:61). In addition, there are some scholars holding that the characteristic of film language should be spoken rather than listening or something like this. Anyway what they argued are the same as the general. Then how to understand such characteristics?

Listening, it refers to the fact that the ways to appreciate the language in literature works and language in films are different, one is reading and the other is listening. However, no matter in what language, there exist homophones, it is easy to distinguish them by reading but difficult by listening to them, and thus they would cause confusion.

Comprehensiveness, it means that stories in films are composed of various factors such as figures, environment, dialogues and so on, and anything wrong with them would cause misunderstanding.

Instant and popularity, they are regarding the features that time for appreciate films is limited, so language in films should be easy and popular to understand, vague words and expressions would offend audiences. At the same time, due to the limitation in subtitle, some details can be added to help audiences understand films, and thus language in films has to be selected carefully.

Based on such characteristics, some difficulties would be bound to be caused when audiences watch oversea films. So, methods have been found to translate overseas films to help audiences in world enjoy them, and Newmark's translation theory is no doubt one of the most suitable methods to apply into this field. 


\section{Newmarker's Translation Theory}

Newmark Peter is one of the most outstanding translation theorists in contemporary Britain, over the years, he has been engaged in research work of translation theory and practice, and has put forward his own opinions on many translation theories. Meanwhile, his own translation theories are involved in many fields. According to Karl Bühler's theory of language, he proposed text classification. He believes that there are only three types of texts: expressive text, informative text and vocative text. On the basis of this, he also proposed his eight translation methods. They are: Word for word translation, Literal translation, Faithful translation, Semantic translation, adaptation, Free translation, Idiomatic translation, and Communicative translation.

Newmark used a flat bottom $\mathrm{V}$ graphics to illustrate the characteristics of these approaches, and concluded which one was more focused on the target language, which focused more on the source language. By comparison, Peter Newmark held that among these approaches, word for word translation emphasized the source language most, and the target language was primarily considered by adaptation. He also pointed out that only semantic translation and communicative translation can achieve accurate and smooth translation.

The purpose of semantic translation is to accurately reproduce the author's original meaning by means of expressions within framework and semantic meaning of the target language and it requires that the translation should try to be close to the original one, which is similar to Eugene Nida's formal equivalence but is not the form so mechanical and absolute as formal equivalence. Semantic translation is often used in the translation of literature, science and technology, and other similar texts, which equally emphasize language and content of the original one. Communicative translation is to try to make translation affect readers target language in the same way as the original text to the source language readers. The focus of communicative translation is to convey information in the language, culture and pragmatic style of the target language, rather than copy the original text faithfully. This is not exactly the same as Nida's dynamic equivalence, either. These two methods can complete the communicative function in a certain extent, but are not completely on an equal footing.

\section{Newmark's Translation Theory in the Translation of films}

Although Peter Newmark's translation theory does not provide a specific targeted strategies for subtitle translation, but his theory in translation is widely used. As a kind of popular entertainment, films have their own unique styles, but in the process of translation, it is not only feasible to reproduce the original features and styles, but also the goal of translators. In order to achieve this goal, the translator tends to give up his own style, and strive to be consistent with the original. Because of the differences between languages and cultures, it is inevitable for translators to encounter differences from the original in the process of translation. Cultural exchange is also one of the purposes for films import and export, and using the most similar languages to transfer characteristics of original films to keep translations as "authentic" as the original can achieve the best effects. So as to maintain the original styles and features, Semantic translation is often used in the translation.

\subsection{The Application of Semantic Translation}

\section{(1) Translation of Titles}

In order to maintain the cultural transmission, semantic translation tends to be used in some of the films' titles so that audience can understand and feel foreign cultures brought by the translation curiously and actively.

For instance, “Citizen Kaine” is translated into 《公民凯恩》, ”The Mummy” into 《木乃伊》, “The Godfather” to 《教父》, “Chicago” into 《芝加哥》, “Saving Private Ryon” into 拯救大兵瑞 恩》 and so on..

In order to transfer traditional Chinese culture, Director Ang Lee’s works 《卧虎藏龙》was 
translated into "Crouching Tiger, hidden dragon". Again, 《建国大业》 was translated into "the Founding of a Republic", 《画皮》 was translated into "painted skin" etc..

(2) Translation of Dialogues

In the English movie "Wuthering Heights", there is a sentence,Cathy expressed her love in a passionate language, "and" in a sentence, expressing her love for the hero. And love, like music, is the common language of the world, and audiences can feel her. So the sentence was translated into:

Healthcliff: I don’t care how long I wait-if I can only lay him back! It was translated into

我不在意等多久, 只要能让他付出代价。Here semantic translation can reflect Heathcliff's hatred and revenge, and is more in line with the emotion the original films convey.

In Chinese movie "The Message", whenWu Zhiguo told Li Yuming how his explained his identity to GU Xiaomeng, there is a sentence“我在阳台唱起那段“空城计”, 她才知道我是自己 人” translated into "When I start singing 'the Empty City', that she learnt I was one of her comrades.” And Commander Zhang’s sentence “我管教我的狗, 你笑什么?” is translated into “I am disciplining my dog, what is so funny about it?”.

Here“空城计'is a typical Chinese cultural word, along with the transmission of culture, most foreigners can understand it and thus, it is translated into 'the Empty City'by semantic translation. Then in another sentence, though the dogs in the western culture is commendatory, but in the biblical culture, they are vile animals, coupled with the specific circumstances, such a translation does not affect the understanding but more vivid to convey the source language culture.

\subsection{The Application of Communicative Translation}

In order to maintain the style and cultural characteristics of the original works, the translators often use semantic translation, but understanding and acceptance of the target audiences have to be considered, and therefore, communicative translation is sometimes essential.

(1) Translation of Titles

For example, the English movie "Waterloo Bridge”, if it is translated into 《滑铁卢桥》, even though it keep the title as "authentic" as the original, it will be very difficult for audiences to get any information, and some Chinese audiences may associate it with Napleon. But if it is translated into 《魂断蓝桥》, then most Chinese audiences can guess it is about a beautiful but heart-rending love story because in China, there was also a similar story happened in “蓝桥”. Also the movie "Casablanca" is translated into《北非谍影》, "Pretty Woman" into《风月 俏佳人》, "Tomb Raider" into 《古墓丽影》; Chinese movie, 《十月围城》into the Bodyguards and assassins ", 《精武英雄》into “Fist of Legend” and so on. These examples illustrate communicative translation can achieve the communication effectively.

(2) Translation of Dialogues

In terms of translation of dialogues in films, communicative translation is often adopted because of differences of languages and cultures.

For example, in the film " The Shawshank Redemption ", new inmate fatty cried loudly, and guard Hadley was very angry. e warned that fat said: "you shut up, or I will sing you a lullaby". The meaning of lullaby in this sentence is the cradle, then the sentence literally means "otherwise I will give you a cradle song", if it is translated in this way, it is absolutely wrong. Therefore, in order to avoid the misunderstanding of audiences, it should be translated into "否则有你受的".

In Chinese movie "The Grand Master", during the Japanese invasion of China Ye Wen said “我 这个人喝惯了珠江水, 这日本的米, 吃不惯”., if the English translation is only faithful to the original, foreign audiences can not receive“珠江水” in fact carrying his love for his hometown. So it is translated into "I 'd rather starve than eat Japanese rice. ", which can convey the image of the determination of resistance to Japanese invasion to make foreign audiences understand the situation in China at that moment. This is a good way to communicate with audiences.

Newmark's semantic translation and communicative translation are different, but not in conflict, and the combination of these two methods can achieve excellent translation works. 


\section{Conclusion}

The characteristics of film make it a unique part in translation field, and the quality of film translation directly influences the pleasure of audiences. Therefore, translators must carry on the translation under appropriate translation theories. Newmark's translation theory is not direct for film subtitle translation, but it has been applied widely. Of course, Newmark's theory is not extreme translation strategy but in the translation of "the golden mean". It is neither too free nor too stiff, and therefore its application in the translation of films will undoubtedly improve the quality of translation works.

\section{References}

[1] C.B. Zhang. An Exploration on the Translation of Filmograpgy [J]. Chinese Translation, (1998) No.2 p 50-53

[2] S.C. Qian. Translation of Filmograpgy ---the Increasing Important Part in the Field of Translation [J]. Chinese translation, (2000) No.1 p 61-65

[3] N.Peter Approaches to Translation Shanghai Foreign Language Education Press, China 2001 p38-70,176-180

[4] Y.L. Liu, Z.J. Yang. "On the 'Domestication' and 'Alienation'" [J]. China Translation, (2002) No.6 p 20-24

[5] X J. Zhu, F.Y.Yang The Dichotomy of Contemporary Western Translation Theories--- Taking Nida, Newmark and Nord and Lawrence Venuti as Examples [J]. Academic Journal of PLA University of Foreign Languages, Vol.29 (2006) No.5, p.79-81 